Review Article

\title{
EXPLORING THE EFFICACY AND SAFETY OF CANNABIS IN THE MANAGEMENT OF FIBROMYALGIA
}

\author{
AMOL SAGDEO ${ }^{1}$, AYMAN ASKARI ${ }^{2}$, PATRICK BALL ${ }^{3}$, HANA MORRISSEY ${ }^{4}$ \\ 1,2Clinical Fellow in Rheumatology, the Robert Jones and Agnes Hunt Orthopaedic Hospital, NHS Foundation Trust, SY10 7AG United Kingdom, \\ 3,4The University of Wolverhampton, Faculty of Science and Engineering, School of Pharmacy, Wulfruna Street, WV1 1LY United Kingdom \\ Email: hana.morrissey@wlv.ac.uk
}

Received: 12 Sep 2021, Revised and Accepted: 15 Nov 2021

\begin{abstract}
Fibromyalgia is a chronic health condition characterized by chronic pain fatigue, sleep disturbances and many other symptoms affecting a patient's quality of life. Patients with fibromyalgia often visit rheumatology outpatients with a long list of symptoms and often receive multiple medications. Many have seen multiple specialists and have done a lot of reading about alternative modalities of treatment. The limited effectiveness of conventional therapy coupled with widespread media attention raises the question of cannabis use.
\end{abstract}

This review examines the literature on cannabinoid use in fibromyalgia against the context of the international variation in legal frameworks, the available products and the outcomes reported. A detailed review was performed using the EMBASE and PUBMED databases.

It was concluded that despite the interest in the use of cannabinoids in the management of fibromyalgia, there is insufficient evidence to prescribe the currently available licensed medicines or to recommend the complementary health products available for legal purchase.

There is a need for more global clinical randomised trials to accurately determine medicinal cannabis short and long-term long efficacy and safety for its acute and chronic use.

Keywords: Fibromyalgia, Medicinal cannabis, Chronic pain, Fatigue, Licensed medicines

(C) 2022 The Authors. Published by Innovare Academic Sciences Pvt Ltd. This is an open access article under the CC BY license (https://creativecommons.org/licenses/by/4.0/) DOI: https://dx.doi.org/10.22159/ijcpr.2022v14i1.44109 Journal homepage: https://innovareacademics.in/journals/index.php/ijcpr

\section{INTRODUCTION}

Fibromyalgia (FM) is the label applied to a chronic pain syndrome. After around $30 \mathrm{y}$ of intensive study, it remains poorly understood [1]. The condition is associated with chronic pain, fatigue and disturbed sleep patterns that all negatively impact a patient's quality of life (QoL). The global incidence is around $2.7 \%$ of the population are affected [2] overall but within Europe it is reported as around of which $4.7 \%$ [3]. It is the third most common rheumatic condition, with only lumbar pain and osteoarthritis being more common [4]. Conventional treatments for pain components of FM include paracetamol, nonsteroidal anti-inflammatory drugs and opioids, which are frequently used with antidepressants. However, while the conventional therapy achieves chronic pain reduction of approximately $50 \%$, this is only 10 $20 \%$ better than placebo [5-8]. These poor outcomes prompted many patients to look for alternatives, such as cannabinoids, which is widely discussed in on social media, leading many patients to express interest in trying their use and some to report self-medicating with medical, commercial and/or illicitly obtained cannabinoids $[9,10]$. Medical cannabis treatment is not currently approved for FM in the UK, but has been extensively investigated for chronic pain management internationally [10-16].

According to the UK national health services (NHS), the traditional management for FM ranges from simple antalgics, exercise and CBT or psychotherapy to the use of opioids, antidepressants, antiepileptics and muscle relaxants [17]. The listed symptoms are all or some of: increased sensitivity to pain, extreme tiredness (fatigue), muscle stiffness, difficulty sleeping, problems with mental processes (known as "fibro-fog"), such as problems with memory and concentration, headaches and irritable bowel syndrome (IBS), a digestive condition that causes stomach pain and bloating [17].

\section{Cannabinoids and chronic pain pathophysiology}

Cannabis and cannabinoids are reported to modulate pain and reduce inflammation through the endocannabinoid system. Cannabinoid receptors are distributed throughout central and peripheral nerves, with lower numbers found in the brain stem.
They also occur in peripheral, non-nervous tissue [18]. The endogenous molecules that bind to these receptors are derived from fatty acid metabolism which is ubiquitous within the body. Endocannabinoids are believed to modulate nociceptive sensory pathways and alter pain perception in chronic pain states $[19,20]$. It has further been suggested that a deficiency of endocannabinoids may be part of the pathophysiology in FM [21]. An alternative theory is that stress may be a major component in FM [22]. Modulation of stress and inflammation to improve emotional and cognitive functioning appears an attractive option in FM management [23-25]. Failed or inadequate response to conventional analgesics, and media reporting, leads many patients to consider cannabis to help control their FM symptoms, as it has been reported to be effective in other chronic pain conditions, without serious side effects [26,27]. The identification and characterization of the endocannabinoid system has triggered an increase in research, but to date, there are few and limited clinical trials of cannabinoids in FM. Small studies with short-term follow-up, and a wide variation in products and approaches used, arising from the wide variations in international regulations and controls, limit their utility as a basis for public health policy [28-31].

\section{Cannabinoid receptors}

Cannabinoid receptor-1 (CB1) is a G-protein coupled receptor linked to the psychotropic effects of cannabis. CB1 is widely distributed in the brain, demonstrating high concentrations in the frontal cortex, basal ganglia and cerebellum, on axons and presynaptic terminals [32]. CB2, is similarly a G-protein coupled receptor, more commonly found on peripheral cells, particularly within the immune system. The CB2 variant Q63R has been linked with autoimmune conditions diseases such as coeliac disease and immune thrombocytopenic purpura, making it of particular interest in rheumatology [33].

Many cannabinoids have been identified, and the number present, and their relative proportions, vary as discussed below [34]. Two of the principal components of therapeutic interest are tetrahydrocannabinol (THC) and cannabidiol (CBD) $[34,35]$. THC is 
the major psychoactive substance reported to affect mood, orientation, appetite and pain perception. CBD is not psychoactive, but is reported to have analgesic, anxiolytic and anti-inflammatory effects [36]. At the receptor level, for CB1, THC is a partial agonist whilst CBD is a negative allosteric modulator [36].

Due to their varying properties and molecular interactions, the relative proportion of THC to CBD in cannabis products are believed to be the primary determinants of the effects and adverse effects observed; however, many other cannabinoids also possess activity giving rise to unique patterns seen with particular products and delivery methods [35]. This is also important in terms of ongoing consistency and quality control in products not subject to the legal controls required for licensed medicinal products [38].

\section{Trials of medical cannabis in fibromyalgia}

A Cochrane review in 2016 did not support the use of cannabinoids in FM [38]. Only two RCTs were included. Both studies focussed on nabilone, and showed promising results, with one trial demonstrating that nabilone effectively reduced anxiety, pain and Fibromyalgia Impact Questionnaire (FIQ) scores [30], and that it was superior to amitriptyline in resolving sleep disturbance, but without improvement in mood, pain or QoL [31]. The studies were limited by small sample size and short duration of follow-up. The authors noted that, neither herbal, plant-based nor were synthetic cannabis products currently licensed for FM in any jurisdiction. A trial of a pharmacological cannabinoid preparation in FM for sleep disturbance [40] $(\mathrm{n}=2705)$, used an online questionnaire for selfreporting. Only 383 (14\%) responses were received. Only 44\% of those who used cannabis (84\%) used medical cannabis (MC), and $55 \%$ of them used it in combination with commercial cannabis (CC). Only those who used CC alone or in combination with MC, showed improvement in pain (94\%), sleep (93\%), depression (87\%), anxiety (62\%), ability to work (64\%) and ability to drive (74\%) [41]. In another study by Habib and Artul [42] MC was used $(n=26,18-$ $34 \mathrm{~g} /$ month for up to $22 \mathrm{mo}$ ). Using the FIQ, patients self-reported improvements in all parameters. Additionally, 50\% stopped taking any other medications for fibromyalgia [42]. The review of Banerjee et al. supported these findings [43]. The review by Gonen and Amital [44] discussed that chronic pain including FM is common component in all rheumatoid diseases, and does not respond well to traditional medications. The authors acknowledged the use of MC in the treatment of FM and that the evidence on long-term efficacy and safety are still controversial. Animal studies have shown accumulated immune-modulatory effect, however, this is not yet studied in human to the same extent [44].

Sagy et al. [45] found that in their sample ( $n=367,82 \%$ females), the use of MC for 6 -months reduced pain significantly $(\mathrm{p}<0.001)$ and $81 \%$ of patients achieved remission. The authors noted there is lack of standardisation of MC compounds and regimens, which is hindering the compilation of evidence from the current literature. Boehnke et al. [46] used a cross-sectional, anonymous survey to examine CBD efficacy in FM (n=2701). Participants self-reported reduction in pain on a scale provided, and only $50 \%$ reported minor side effects.

Van de Donk [47] conducted a placebo-controlled 4-way crossover trial comparing 4-varieties of inhaled MC in the treatment of FM compared to a placebo. None of the tested varieties was superior to placebo in managing spontaneous or 'electrical' (neuropathic) pain. In another study, Yassin and Robinson [48] concluded that conventional analgesia provided slight pain improvement in FM compared to baseline, whilst a greater improvement was achieved when MC was added and was maintained at 6 mo follow-up. Chaves et al. [49] explored the benefit of a THC-rich cannabis oil on symptoms and QoL of FM in 17 women (8 in intervention group and 9 in placebo group) with a low socioeconomic profile in Brazil. The dose was titrated up according to symptoms during an 8-weeks period and FIQ was used before and after dosing. The authors concluded that the cannabis group had a significant $(\mathrm{P}<0.001)$ reduction in their FIQ on the "feel good," "pain," "do work," and "fatigue" items compared to the placebo group at the end of the intervention, however long-term benefit and safety were not assessed. The systematic review by Fitzcharles et al. [28] included 4
RCTs covering 160 patients with FM, RA or musculoskeletal pain, examining the efficacy of nabilone. They found no significant difference between nabilone and placebo with respect to pain relief in FM patients and in patients with musculoskeletal pain. However Cameron et al. [50] noted serious methodological limitations in published studies, that prevent researchers and policymakers from being able to make a definitive conclusion on cannabinoid use for pain management in FM.

\section{UK National institute for health and care excellence (NICE)}

The committee noted that some studies concluded chronic pain improvement but that the improvement was statistically and clinically insignificant (mean of 0.4 on a scale ranging from 0 to 10 ) and patients continued to use other pharmacological pain management products at the same level. They concluded the cost outweighed the benefit, making it not sustainable. They found there was no evidence for the use of CBD alone (either as a pure product or containing traces of THC). Therefore, the committee recommended that CBD should not be offered unless as part of a clinical trial. People who have FM or persistent treatment-resistant neuropathic pain are often taking high doses of medicines for pain relief over long periods. These can cause nausea, drowsiness, mood disturbance and fatigue. The committee noted that this is a significant population of people with chronic pain (around 15\%). They recommended further research on CBD in adults with FM and/or treatment-resistant neuropathic pain [51].

\section{Possible reasons for the current poor evidence}

It is clear that even optimal therapy with conventional analgesics leaves many patients with residual pain and seeking further solutions, and the internet has empowered discussion across international boundaries. Patients are communicating, and as shown in the study by $\mathrm{Li}$ [10] many are self-medicating or at least experimenting with self-medication using a wide variety of forms and products. As stated in the EU report [38] this need, in the context of the diverse international legislative framework and low levels of control of 'natural products' has led to a very wide diversity in products. Medical products are strictly controlled, containing accurately defined amounts of one or more stated ingredients or extracts. The controls for complementary therapies are less rigid. A licensed medicine will normally contain between $99 \%$ and $101 \%$ of the stated ingredient. Even when a plant extract, it will normally be accurately standardised on one or two stated ingredients, but herein lies an important issue. A typical plant extract will have several hundred identifiable compounds. The total amount, and relative proportions, of these, are affected by; the variety of the plant, the conditions in which it was grown (soil and climatic conditions), the season, time of day and specific weather conditions under which the plant was harvested, storage conditions and processes applied. Common extraction procedures include aqueous (neutral, acid or alkaline) or alcoholic extraction; all of these will produce different proportions of individual compounds. To minimise these variables, clinical trials of complementary products commonly use the product from a single batch.

The study by Li [10] was novel. A smartphone application (App) $\left(\right.$ Releaf $^{\mathrm{TM}}$ ) was used to report the use of the cannabinoids for pain relief, the form used, the relief gained and the side effects experienced in real-time. A total of 2,987 people reported 20,513 cannabinoid administrations. Their results reflected the factors mentioned above. Almost all patients reported pain relief. On a typical pain scale from 0-10 average reported pain relief was 3 points on a par with a mid-level pharmaceutical analgesic. None of the derived products reported was found as effective as the whole cannabis flower. Reported relief varied with different types of pain, although encouragingly for use in FM, it appeared most effective in musculoskeletal pain, but standard deviations were wide, showing large individual variation in response. Use of concentrates appeared to increase reports of negative side effects without increased pain relief compared to whole cannabis.

Greis et al. [17] concentrated upon patients obtaining cannabis products through State of Pennsylvania, licenced cannabis retailer system. Their study of mixed orthopaedic patients treated for 
chronic pain ( $\mathrm{n}=468)$, showed $73 \%$ of participants decreased (and some ceased completely) to use their prescription opioids and $31 \%$ discontinued benzodiazepines, however, again, nearly one third of patients had little or no benefit, and almost $50 \%$ of patients noted feelings of intoxication.

There remains therefore clear evidence that Cannabis can be of considerable benefit to certain patients, with some types of pain, but is very far from being a panacea. The current licenced medical products derived from cannabis show a very different pattern of effects compared to whole plant derived administration methods. A great deal more research is required to clearly establish its role in FM.

Cannabis has well-known drawbacks as a medicine, including the potential for dependence and addiction; risk of motor vehicle accidents, psychotic and psychedelic experiences and cognitive impairment [15], but have been claimed to be relatively less severe than misuse of either prescription or non-prescription opioids [10]. Although studies have linked cannabis use to an increased risk of opioid misuse [15,52], the US experience suggests that extending the legal use of cannabis has reduced opioid misuse amongst patients with chronic pain $[53,54]$.

\section{CONCLUSION}

Recent studies suggest that, in time, the use of cannabinoids will add a useful contribution to pain management in this challenging condition, but the evidence to date does not support the use of the products currently available in the UK. If governments could be persuaded to harmonise the legal framework around cannabis products internationally, this would greatly facilitate the design of larger, multi-centre trials, and encourage the development of products manufactured to the standards for licensed medicines, whilst better controlling the poorly regulated products found in many countries.

Should cannabis-based products be used to manage FM? For the present, not unless as part of controlled and regulated clinical trials.

\section{FUNDING}

\section{No external funding}

\section{AUTHORS CONTRIBUTIONS}

Authors 1 and 2 conducted the initial review and first draft. Authors 3 and 4 reviewed the evidence and completed the final draft of the manuscript.

\section{CONFLICT OF INTERESTS}

No conflict of interest known

\section{REFERENCES}

1. Bazzichi L, Giacomelli C, Consensi A, Giorgi V, Batticciotto A, Di Franco M, Sarzi-Puttini P. One year in review 2020: fibromyalgia. Clin Exp Rheumatol. 2020;38(1);Suppl 123:3-8. PMID 32116216.

2. Wolfe F, Ross K, Anderson J, Russell IJ, Hebert L. The prevalence and characteristics of fibromyalgia in the general population. Arthritis Rheum. 1995;38(1):19-28. doi: 10.1002/art.1780380104, PMID 7818567.

3. Branco JC, Bannwarth B, Failde I, Abello Carbonell J, Blotman F, Spaeth M, Saraiva F, Nacci F, Thomas E, Caubère JP, Le Lay K, Taieb C, Matucci-Cerinic M. Prevalence of fibromyalgia: a survey in five European countries. Semin Arthritis Rheum. 2010;39(6):448-53. doi: 10.1016/j.semarthrit.2008.12.003, PMID 19250656.

4. Spaeth M. Epidemiology, costs, and the economic burden of fibromyalgia. Arthritis Res Ther. 2009;11(3):117. doi: 10.1186/ar2715, PMID 19591654.

5. Hauser W, Urrutia G, Tort S, Uçeyler N, Walitt B. Serotonin and noradrenaline reuptake inhibitors (SNRIs) for fibromyalgia syndrome. Cochrane Database Syst Rev. 2013;1(1):CD010292. doi: 10.1002/14651858.CD010292, PMID 23440848.

6. Häuser W, Walitt B, Fitzcharles MA, Sommer C. Review of pharmacological therapies in fibromyalgia syndrome. Arthritis
Res Ther. 2014;16(1):201. doi: 10.1186/ar4441, PMID 24433463.

7. Moore AR, Straube S, Paine J, Phillips CJ, Derry S, McQuay HJ. Fibromyalgia: moderate and substantial pain intensity reduction predicts improvement in other outcomes and substantial quality of life gain. Pain. 2010;149(2):360-4. doi: 10.1016/j.pain.2010.02.039, PMID 20347225.

8. Sommer C, Welsch P, Klose P, Schaefert R, Petzke F, Hauser W. Opioids in chronic neuropathic pain. A systematic review and meta-analysis of efficacy, tolerability and safety in randomized placebo-controlled studies of at least 4-W durationopioids in chronic neuropathic pain. A systematic review and metaanalysis of efficacy, tolerability and safety in randomized placebo-controlled studies of at least 4 weeks duration. Schmerz. 2015;29(1):35-46. doi: 10.1007/s00482-014-1455-x, PMID 25376548.

9. Li X, Vigil JM, Stith SS, Brockelman F, Keeling K, Hall B. The effectiveness of self-directed medical cannabis treatment for pain. Complement Ther Med. 2019;46:123-30. doi: 10.1016/j.ctim.2019.07.022, PMID 31519268.

10. Hill KP, Palastro MD, Johnson B, Ditre JW. Cannabis and pain: A clinical review. Cannabis Cannabinoid Res. 2017;2(1):96-104. doi: 10.1089/can.2017.0017, PMID 28861509.

11. Giorgi V, Bongiovanni S, Atzeni F, Marotto D, Salaffi F, SarziPuttini P. Adding medical cannabis to standard analgesic treatment for fibromyalgia: a prospective observational study. Clin Exp Rheumatol. 2020;38(1);Suppl 123:53-9. PMID 32116208.

12. Guillouard M, Authier N, Pereira B, Soubrier M, Mathieu S. Cannabis use assessment and its impact on pain in rheumatologic diseases: a systematic review and meta-analysis. Rheumatology (Oxford). 2021;60(2):549-56. doi: 10.1093/rheumatology/keaa534, PMID 33159797.

13. Rocco M, Rada G. Are cannabinoids effective for fibromyalgia? Medwave. 2018;18(1):e7154. doi: 10.5867/medwave. 2018.01.7153, PMID 29474351.

14. Nugent SM, Morasco BJ, O’Neil ME, Freeman M, Low A, Kondo K, Elven C, Zakher B, Motu'apuaka M, Paynter R, Kansagara D. The effects of cannabis among adults with chronic pain and an overview of General Harms: A systematic review. Ann Intern Med. 2017;167(5):319-31. doi: 10.7326/M17-0155, PMID 28806817.

15. Campbell G, Hall WD, Peacock A, Lintzeris N, Bruno R, Larance B, Nielsen S, Cohen M, Chan G, Mattick RP, Blyth F, Shanahan M, Dobbins T, Farrell M, Degenhardt L. Effect of cannabis use in people with chronic non-cancer pain prescribed opioids: findings from a $4 \mathrm{y}$ prospective cohort study. Lancet Public Health. 2018;3(7):e341-50. doi: 10.1016/S2468-2667(18) 30110-5, PMID 29976328.

16. Greis A, Larsen E, Liu C, Renslo B, Radakrishnan A, Wilson-Poe AR. Perceived efficacy, reduced prescription drug use, and minimal side effects of cannabis in patients with chronic orthopedic pain. Cannabis Cannabinoid Res. 2021. doi: 10.1089/can.2021.0088, PMID 34767730.

17. National health services (NHS), Fibromylagia. Available from: https://www.nice.org.uk/guidance/ng144. [Last accessed on 12 Dec 2021].

18. Herkenham M, Lynn AB, Little MD, Johnson MR, Melvin LS, de Costa BR, Rice KC. Cannabinoid receptor localization in brain. Proc Natl Acad Sci USA. 1990;87(5):1932-6. doi: 10.1073/pnas.87.5.1932, PMID 2308954.

19. Di Marzo V, Bifulco M, De Petrocellis L. The endocannabinoid system and its therapeutic exploitation. Nat Rev Drug Discov. 2004;3(9):771-84. doi: 10.1038/nrd1495, PMID 15340387.

20. Guindon J, Hohmann AG. The endocannabinoid system and pain. CNS Neurol Disord Drug Targets. 2009;8(6):403-21. doi: 10.2174/187152709789824660, PMID 19839937.

21. Russo EB. Clinical endocannabinoid deficiency (CECD): can this concept explain therapeutic benefits of cannabis in migraine, fibromyalgia, irritable bowel syndrome and other treatmentresistant conditions? Neuro Endocrinol Lett. 2004;25(1-2):319. PMID 15159679.

22. Van Houdenhove B, Egle UT. Fibromyalgia: a stress disorder? Piecing the biopsychosocial puzzle together. Psychother 
Psychosom. 2004;73(5):267-75. doi: 10.1159/000078843, PMID 15292624.

23. Hillard CJ, Weinlander KM, Stuhr KL. Contributions of endocannabinoid signaling to psychiatric disorders in humans: genetic and biochemical evidence. Neuroscience. 2012;204:207-29. doi: 10.1016/j.neuroscience.2011.11.020, PMID 22123166.

24. Lee MC, Ploner M, Wiech K, Bingel U, Wanigasekera V, Brooks J, Menon DK, Tracey I. Amygdala activity contributes to the dissociative effect of cannabis on pain perception. Pain. 2013;154(1):124-34. doi: 10.1016/j.pain.2012.09.017. PMID 23273106.

25. Uçeyler N, Hauser W, Sommer C. Systematic review with metaanalysis: cytokines in fibromyalgia syndrome. BMC Musculoskelet Disord. 2011;12:245. doi: 10.1186/1471-247412-245, PMID 22034969.

26. Abuhasira R, Schleider LB, Mechoulam R, Novack V. Epidemiological characteristics, safety and efficacy of medical cannabis in the elderly. Eur J Intern Med. 2018;49:44-50. doi: 10.1016/j.ejim.2018.01.019, PMID 29398248.

27. Bar Lev Schleider L, Mechoulam R, Lederman V, Hilou M, Lencovsky O, Betzalel O, Shbiro L, Novack V. Prospective analysis of safety and efficacy of medical cannabis in large unselected population of patients with cancer. Eur J Intern Med. 2018;49:37-43. doi: 10.1016/j.ejim.2018.01.023, PMID 29482741.

28. Fitzcharles MA, Ste-Marie PA, Hauser W, Clauw DJ, Jamal S, Karsh J, Landry T, Leclercq S, Mcdougall JJ, Shir Y, Shojania K, Walsh Z. Efficacy, tolerability, and safety of cannabinoid treatments in the rheumatic diseases: a systematic review of randomized controlled trials. Arthritis Care Res (Hoboken). 2016;68(5):681-8. doi: 10.1002/acr.22727, PMID 26548380.

29. Pacher P, Batkai S, Kunos G. The endocannabinoid system as an emerging target of pharmacotherapy. Pharmacol Rev. 2006;58(3):389-462. doi: 10.1124/pr.58.3.2, PMID 16968947.

30. Skrabek RQ, Galimova L, Ethans K, Perry D. Nabilone for the treatment of pain in fibromyalgia. J Pain. 2008;9(2):164-73. doi: 10.1016/j.jpain.2007.09.002, PMID 17974490.

31. Ware MA, Fitzcharles MA, Joseph L, Shir Y. The effects of nabilone on sleep in fibromyalgia: results of a randomized controlled trial. Anesth Anal. 2010;110(2):604-10. doi: 10.1213/ANE.0b013e3181c76f70, PMID 20007734.

32. Mackie K. Mechanisms of CB1 receptor signaling: endocannabinoid modulation of synaptic strength. Int J Obes (Lond). 2006;30Suppl 1:S19-23. doi: 10.1038/sj.ijo.0803273, PMID 16570100.

33. Malfitano AM, Basu S, Maresz K, Bifulco M, Dittel BN. What we know and do not know about the cannabinoid receptor 2 (CB2). Semin Immunol. 2014;26(5):369-79. doi: 10.1016/j.smim.2014.04.002, PMID 24877594.

34. Ramirez CL, Fanovich MA, Churio MS. Cannabinoids: extraction methods, analysis, and physicochemical characterization. Stud Nat Prod Chem. 2019. Chapter 4;61:143-73. doi: 10.1016/B978-0-444-64183-0.00004-X.

35. Madras BK. Tinkering with THC-to-CBD ratios in marijuana. Neuropsychopharmacology. 2019;44(1):215-6. doi: 10.1038/s41386-018-0217-3, PMID 30232407.

36. Stith SS, Vigil JM, Brockelman F, Keeling K, Hall B. The association between cannabis product characteristics and symptom relief. Sci Rep. 2019;9(1):2712. doi: 10.1038/s41598019-39462-1. PMID 30804402.

37. Hryhorowicz S, Kaczmarek Rys M, Andrzejewska A, Staszak K, Hryhorowicz M, Korcz A, Słomski R. Allosteric modulation of cannabinoid receptor 1-current challenges and future opportunities. Int J Mol Sci. 2019;20(23). doi: 10.3390/ijms20235874, PMID 31771126.

38. Union E. Medical use of cannabis and cannabinoids: questions and answers for policymaking. Lisbon, Portugal: European Monitoring Centre for Drugs and Drug Addiction; 2018. p. 48.
39. Walitt B, Klose P, Fitzcharles MA, Phillips T, Hauser W. Cannabinoids for fibromyalgia. Cochrane Database Syst Rev. 2016;7(7):CD011694. 10.1002/14651858.CD011694.pub2, PMID 27428009.

40. Martel M WL, Sotoodeh R, Vigano A, Moride Y, Canac Marquis M, Gamaoun R, Kalaba M, Beaulieu P, Desroches J, Ware M, Perez J, Shir Y, Fitzcharles M. Factors associated with pain reduction and improved well-being among fibromyalgia patients using medical cannabis. American College of Rheumatology. New Orleans, USA: Arthritis and Rheumatology; 2021.

41. Habib G, Avisar I. The consumption of cannabis by fibromyalgia patients in Israel. Pain Res Treat. 2018;2018:7829427. doi: 10.1155/2018/7829427, PMID 30140459.

42. Habib G, Artul S. Medical cannabis for the treatment of fibromyalgia. J Clin Rheumatol. 2018;24(5):255-8. doi: 10.1097/RHU.0000000000000702, PMID 29461346.

43. Banerjee R, Erridge S, Salazar O, Mangal N, Couch D, Pacchetti B, Sodergren MH. Real world evidence in medical cannabis research. Ther Innov Regul Sci. 2021. doi: 10.1007/s43441021-00346-0, PMID 34748204.

44. Gonen T, Amital H. Cannabis and cannabinoids in the treatment of rheumatic diseases. Rambam Maimonides Med J. 2020;11(1). doi: 10.5041/RMMJ.10389, PMID 32017684

45. Sagy I, Bar Lev Schleider L, Abu Shakra M, Novack V. Safety and efficacy of medical cannabis in fibromyalgia. J Clin Med. 2019;8(6). doi: 10.3390/jcm8060807, PMID 31195754.

46. Boehnke KF, Gagnier JJ, Matallana L, Williams DA. Cannabidiol use for fibromyalgia: prevalence of use and perceptions of effectiveness in a large online survey. J Pain. 2021;22(5):55666. doi: 10.1016/j.jpain.2020.12.001, PMID 33400996.

47. van de Donk T, Niesters M, Kowal MA, Olofsen E, Dahan A, van Velzen M. An experimental randomized study on the analgesic effects of pharmaceutical-grade cannabis in chronic pain patients with fibromyalgia. Pain. 2019;160(4):860-9. doi: 10.1097/j.pain.0000000000001464, PMID 30585986.

48. Yassin M, Oron A, Robinson D. Effect of adding medical cannabis to analgesic treatment in patients with low back pain related to fibromyalgia: an observational cross-over single centre study. Clin Exp Rheumatol. 2019;37(1)Suppl 116:13-20. PMID 30418116.

49. Chaves C, Bittencourt PCT, Pelegrini A. Ingestion of a THC-rich cannabis oil in people with fibromyalgia: A randomized, doubleblind, placebo-controlled clinical trial. Pain Med. 2020;21(10):2212-8. doi: 10.1093/pm/pnaa303, PMID 33118602.

50. Cameron EC, Hemingway SL. Cannabinoids for fibromyalgia pain: a critical review of recent studies (2015-2019). J Cannabis Res. 2020;2(1):19. doi: 10.1186/s42238-020-00024-2, PMID 33526114.

51. NICE. Cannabis-based medicinal products. NICE Guideline. London: National Institute for Health and Care Excellence; 2019. p. NG144. Available from: https://www.nice. org.uk/guidance/ng144. [Last accessed on 12 Dec 2021]

52. Olfson M, Wall MM, Liu SM, Blanco C. Cannabis use and risk of prescription opioid use disorder in the United States. Am J Psychiatry. 2018;175(1):47-53. doi: 10.1176/appi.ajp.2017. 17040413, PMID 28946762.

53. National Academies of sciences E, Medicine, health. Medicine D, Board on Population H, Public Health P. The National Academies Collection: Reports funded by National Institutes of Health. The Health Effects of Cannabis and Cannabinoids: The Current State of Evidence and Recommendations for Research. Washington (DC): National Academies Press (US). Copyright 2017 by the National Academy of Sciences. All rights reserved; 2017.

54. Vigil JM, Stith SS, Adams IM, Reeve AP. Associations between medical cannabis and prescription opioid use in chronic pain patients: A preliminary cohort study. PLoS ONE. 2017;12(11):e0187795-e. 